\title{
A review of combined economic emission dispatch for optimal power dispatch with renewable energy
}

\author{
N.F. Aswan', M.N. Abdullah', A.H. Abu Bakar ${ }^{3}$ \\ ${ }^{1,2}$ Green and Sustainable Energy (GSEnergy) Focus Group, Faculty of Electrical and Electronic Engineering, \\ Universiti Tun Hussein Onn Malaysia, Malaysia \\ ${ }^{3}$ UM Power Energy Dedicated Advanced Centre (UMPEDAC), University of Malaya, Malaysia
}

\begin{tabular}{l} 
Article Info \\
\hline Article history: \\
Received Jan 9, 2019 \\
Revised Apr 11, 2019 \\
Accepted May 2, 2019 \\
\hline
\end{tabular}

\section{Keywords:}

Combined economic emission dispatch

Optimal power generation

Optimization method

Renewable energy

\begin{abstract}
This paper provides comprehensive review of recent formulation and solution of combined economic emission dispatch problem considering renewable energy. Generally, power dispatch plays an important role in power generation system that mainly depends on the fossil fuels. Rapid depletion of these sources cause a limitation and increase the fuel price. At the same time, the poisonous gases emit by the thermal generator causes a long term environmental pollution. An extensive researches have been conducted for last few decades by considering Renewable Energy (RE) in power generation system as an alternative source. Therefore, Combined Economic Emission Dispatch (CEED) of thermal and renewable energy resources currently formulated in power dispatch problem. The optimization methods that commonly used to solve the CEED problem are categorized as traditional method, non-conventional method and hybrid method. It can be concluded that non-conventional and hybrid method have great and superior solution for solving multiobjective economic emission dispatch problem. The recent research related to CEED with RE are summarized in terms of methods, test cases, conditions, types of RE and constraints. Thus, it can be useful references for the research in this area.
\end{abstract}

Copyright (C) 2019 Institute of Advanced Engineering and Science. All rights reserved.

\section{Corresponding Author:}

M. N. Abdullah,

Green and Sustainable Energy (GSEnergy) Focus Group,

Faculty of Electrical and Electronic Engineering,

Universiti Tun Hussein Onn Malaysia,

Parit Raja, 86000 Batu Pahat, Johor, Malaysia.

Email: mnoor@uthm.edu.my

\section{INTRODUCTION}

Power generation is known as a large network system that responsible in supplying the electricity while power dispatch plays a big role in power system planning and scheduling. Power dispatch is responsible in planning an optimal and effective power output of committed generator to meet the required power demand and system constraints [1].

Economic Dispatch (EcD) is one of optimization problem that deals with the reduction of fuel costs to meet the power demand [2]. Instead of minimizing the cost in EcD problem, the Emission Dispatch (EmD) problem also need to pay more attentions in the power dispatch problem. EmD is referred to the minimization of the burning fossil fuels that have discharge various harmful particles in the air such as nitrogen oxides $\left(\mathrm{NO}_{\mathrm{x}}\right)$, sulfur dioxide $\left(\mathrm{SO}_{2}\right)$ and carbon dioxide $\left(\mathrm{CO}_{2}\right)$ [3]. The minimization of both fuel cost and emission of pollutant form a multi-objectives optimization problem called Combined Economic Emission Dispatch (CEED) [4] where these problems are commonly conflicted to each other. Therefore, the best optimal solution of CEED become important optimization problem to be solved in power system scheduling. 
The rapid depletion of fossil fuels introduced renewable energy sources as one of the alternatives to be implement in power system. These great innovation are accepted and many researcher are started to include these green technologies into power dispatch problem [5-7]. By involving the green technologies, the complexity CEED formulation and constraints are also increased and attract the researcher to focus in this research [7-9].

This paper presents the fundamental concept of power dispatch including Economic and Emission Dispatch. It also provides comprehensive review of Combined Economic Emission Dispatch (CEED) considering renewable energy. The critical analysis and summary of the related previous study are highlighted in the table form. Therefore, it can guide researcher to find the suitable research direction in this area.

\section{CONCEPT OF POWER DISPATCH}

The global are facing a major depletion on fossil fuels, thus making these sources become limited and affecting the price as well. Therefore, the Economic Dispatch $(\mathrm{EcD})$ is introduced as a solution to minimize the total fuel cost $\left(C_{T}\right)$. The main objective of the EcD is to reduce the fuel cost of the generating unit. The EcD formulation can be expressed in quadratic formulation as [5]:

$$
C_{T}=\sum_{i=1}^{N_{G i}} a_{i}+b_{i} P_{G i}+c_{i} P_{G i}^{2}
$$

where $a_{i}, b_{i}$, and $c_{i}$ are the fuel cost coefficients of the $i$ th generator while $P_{G i}$ known as the power of the generator. By considering valve point effect, the non-convex fuel cost function $\left(C_{i}\right)$ can be formulate as [10]:

$$
C_{i}=a_{i}+b_{i} P_{G i}+c_{i} P_{G i}^{2}+\left|e_{i} \sin \left(f_{i}\left(P_{G i}^{\min }-P_{G i}\right)\right)\right|
$$

where $e_{i}$ and $f_{i}$ are the fuel cost coefficients of the $i$ th generator due to valve point effect.

However, burning fossil fuels can emit a harmful particle in the air such as sulfur dioxide $\left(\mathrm{SO}_{2}\right)$, nitrogen oxide $\left(\mathrm{NO}_{\mathrm{x}}\right)$ and carbon dioxide $\left(\mathrm{CO}_{2}\right)$. Therefore, Emission Dispatch $(\mathrm{EmD})$ is proposed with the goal to minimize the emission of the hazardous particle of the generating unit. The mathematical formulation of emission $\left(E_{i}\right)$ can be expressed as [11]:

$$
E_{i}=\alpha_{i}+\beta_{i} P_{G i}+\gamma P_{G i}^{2}+\varepsilon_{i}\left(\exp \left(\delta_{i} * P_{i}\right)\right)
$$

where $\alpha_{i}, \beta_{i}, \gamma_{i}, \varepsilon_{i}$ and $\delta_{i}$ is the emission coefficients of $i$ th generating unit.

These two single objectives can combine to form Combined Economic Emission Dispatch (CEED) that minimized both fuel cost and emission of the generating unit simultaneously [11]. The CEED optimization problem can be define as [1]:

$$
\min F=\sum_{i=1}^{n}\left(C_{i}\left(P_{G i}\right)+h_{i} E_{i}\left(P_{G i}\right)\right)
$$

where $\min F$ is the objective function to be minimized, $C_{i}$ and $E_{i}$ is the fuel cost and emission function of the $i$ th generating unit and $h_{i}$ is the price penalty factor. This approach are to convert the multiobjective problem into a single objective problem[11]. Thus, $h_{i}$ can be calculated as follows [11]:

$$
h_{i}=\frac{a_{i}+b_{i} P_{G i}+c_{i} P_{G i}^{2}+\left|e_{i} \sin \left(f_{i}\left(P_{G i}^{\min }-P_{G i}^{\max }\right)\right)\right|}{\left(\alpha_{i}+\beta_{i} P_{G i}+\gamma P_{G i}^{2}+\varepsilon_{i}\left(\exp \left(\delta_{i} * P_{i \max }\right)\right)\right.}
$$

The effect of fossil fuel brings up a renewable energy as an alternatives way to solve the economic and environmental issues. There are various green technologies have been developed and the most popular are hydro, solar and wind sources while biomass, tidal and geothermal are starting to strike up in global market. 
Power dispatch problem can be formulated in two different condition which are in static condition or dynamic condition [11]. Static condition is aimed to allocate the generating unit in a scheduling horizon normally one hour while dynamic condition is the performance over twenty-four hours a day. Obviously the formulation of the dynamic condition will be more complex compared to static condition. Although the dynamic formulation is difficult due to the large dimensionality but the performance in term of accuracy is high [3]. Several researches have been successfully solve the dynamic CEED problem. Normally, CEED has been applied on thermal cases only and the formulation is simpler. Meanwhile, to solve these multi-objective problem by considering the renewable energy, the formulation might be more complex subject to constraint. This is one of the good choice we have to overcome the limitation of fossil fuels and reducing the pollutant. However, these renewable energies also confronting the constraints especially uncertainty of the weather.

\section{CEED WITH RENEWABLE ENERGY}

Despite from fossil fuel, renewable energy is started to be implement widely on power generation as an alternatives sources. Renewable energy is not deplete as compared to the fossil fuels that are now facing up a depletion process. Thermal generator has own constraints as well as renewable energy generators.

In 2012 [12], A.Ahmadi proposed a method for self-scheduling of hydro-thermal problem. A valvepoint effect problem has been linearized in this multi-objective problem. Instead of fix rate, a dynamic ramp rate limit is used to optimize the problem. This problem is studied on IEEE-118 bus considering prohibited operational zones, ramp rate limit and fuel limitations. An analytic method using lexicographic optimization and hybrid augmented-weighted $\varepsilon$-constraint technique is used and efficiently solved the problem.

In 2013 [6], H.T. Jadhav solved the economic emission dispatch considering wind power as stochastic variable. An ABC algorithm is a hybrid with PSO algorithm and applied to IEEE-30 bus test system consists of two wind farm and six thermal units. The proposed method are applied to three different cases considering valve point effect, prohibited zones, ramp rate limit and others. The proposed method has good performances on computational efficiency and converges fast than PSO and ABC. A. Immanuel Selvakumar proposed a multi-objective short-term hydrothermal scheduling (MSTHTS) including the economic and emission as the objective functions [13]. Hybrid method has been carried out by integrating society-civilization algorithm (SCA) and particle swarm optimization algorithm (PSO) thus introducing civilized swarm optimization (CSO) where the ability of local and global searching are balanced. The performance of CSO has been illustrated on two hydrothermal test systems in terms of solution optimality, consistency and execution time. As a result, proposed CSO is more consistent and faster than the previous methods.

In 2014 [11], Naveed Ahmed Khan proposed a solar generation on combined emission economic dispatch of the power system. The solar generation are tested statically and dynamically with full and reduced radiation. A popular method, particle swarm optimization method has been approach on six conventional and thirteen photovoltaic plant by considering power balance and generator limit constraints. In [14], the authors proposed a fixed head hydro thermal environmental economic dispatch possesses various constraints including generator limit constraint, water availability constraints and power balance constraints. An improved multi-objective estimation of distribution algorithms is approach to solve the multi-objective problems of fixed two hydro unit and two and four thermal generator.

In 2015 [8], Jamshid Aghaei proposed a self-scheduling of hydro-thermal considering ramp rate limit, multi-head power discharge characteristic of the hydro, spillage of reservoirs, prohibited operating zones and operating services of the thermal plants. The problem is applied on IEEE-118 bus of 54 thermal unit and 8 hydro unit by $\varepsilon$ constraint and generate Pareto set. To validate the superior of the method, the result obtained is compared to the weighted sum method, differential evolution, quantum-behaved particle swarm optimization algorithm, hybrid multi-objective cultural algorithm and evolutionaryprogramming based interactive fuzzy satisfying method. A wind-thermal economic emission dispatch include the coordination of power allocation form wind and thermal power generation is then proposed by Shanhe Jiang [15]. A new develop optimization method known as gravitational acceleration enhanced particle swarm optimization algorithm is proposed to solve this bi-objective problem. The proposed hybrid method quickly converges when compared to gravitational search algorithm and particle swarm optimization algorithm.

In 2016 [10], Ali Ghasemi addresses the effect of wind on economic emission dispatch. An OLHBMO algorithm is suggested to solve the IEEE-30 bus 6 unit, IEEE 118-bus 14 unit and IEEE 118bus 40 unit with valve point effect, security constraint, equality and inequality constraint and prohibited operating zones. Next, Naveed Ahmed Khan presents a combined economic emission dispatch with solar generation on IEEE-30 bus system[4]. A hybrid method are applied to solve the problem with network security constraints. At the same time, Shunjiang Lin proposed a normalized normal constraints algorithm to be applied on multi-objectives problem in large scale power system with wind and pumped storage 
hydroelectric stations [16]. Yimu Fu has minimized the power purchase cost and pollutant gas emission on stochastic wind thermal generation [9]. Interior point method has been applied to solve IEEE- 39 bus and Real 1534-bus power system with added of wind plant. The constraints are including power balance constraint, conventional unit output, wind farm output and pumped storage station output. As a result, a preliminary exploration is performed with high computing clusters.

In 2017 [1], optimization of economic emission dispatch with solar generation has been proposed by C.Shilaja and K.Ravi. This bi-objectives problem are solved by eFPA and BFPA by including generator constraints, power balance constraints and renewable energy constraints. About twenty solar and five thermal generator are used on IEEE-30 bus and IEEE-57 bus system with full solar radiation and reduced solar radiations. Mohammad Reza Andervash then present an economic emission dispatch of thermal with the presence of hybrid electric car and correlated wind power plants [17]. The uncertainty of the wind plant, the generator constraints and prohibited operating zones are including as the constraints. The NSGA-II and SPEA method are approach to solve these multi-objective problem. Paper [18] proposed a multi-objective short- term hydrothermal scheduling. The cuckoo search algorithm is modified for improvement and applied on four test system that consider power balance constraints, generator limit and hydraulic constraints.

Gang Liu proposed a dynamic economic emission with wind-thermal plant in paper [19]. A hybrid method, DE and PSO are integrate into DE-PSO algorithm to solve the problem. The result are more superior compared to other method in term of diversity, maximum spread and accuracy. A multi-objective economic environmental power dispatch with stochastic wind-solar-small hydro plant (run of river) is then proposed by Partha P.Biswas [5]. Some of the IEEE-30 bus system has replaced with one wind generator, one solar unit and one combination of solar and hydro unit. MOEA and SMODE are used up to solve the problem by considering the network constraint, prohibited zones and generator capability. The simulation result shows that SMODE outperform MOEA in terms of achieving diversity and convergence.

In 2019 [3], M.Basu proposed multi-area dynamic economic emission dispatch considering hydrowind-thermal power system. The NSGA-II is used for solving complicated real world problem by taking consideration of wind power uncertainty, cascaded hydro plants and valve point effect.

Table 1 summarizes the papers that recent and related research of combined economic emission dispatch with renewable energy where the method, case study, condition, type of renewable energy and constraints are highlighted.

Table 1. Summary of the Paper Related to CEED with Renewable Energy

\begin{tabular}{|c|c|c|c|c|c|c|c|c|c|}
\hline \multirow[t]{2}{*}{ No. } & \multirow[t]{2}{*}{ Ref/Year } & \multirow[t]{2}{*}{ Method } & \multirow[t]{2}{*}{ Test Case } & \multicolumn{2}{|c|}{ Condition } & \multicolumn{3}{|c|}{$\begin{array}{c}\text { Renewable } \\
\text { Energy Source }\end{array}$} & \multirow[t]{2}{*}{ Constraint } \\
\hline & & & & St & $\mathrm{D}$ & $\mathrm{W}$ & $\mathrm{S}$ & $\mathrm{H}$ & \\
\hline 1. & $\begin{array}{c}{[3]} \\
2019\end{array}$ & NSGA-II & $\begin{array}{l}4 \text { reservoir hydro plant, } 2 \\
\text { wind plant and } 10 \text { thermal }\end{array}$ & & $\sqrt{ }$ & & & $\sqrt{ }$ & $\begin{array}{l}\text { Ramp rate limit constraints, } \\
\text { hydraulic network constraints, } \\
\text { tie line capacity constraints }\end{array}$ \\
\hline 2. & $\begin{array}{l}{[19]} \\
2018\end{array}$ & $\begin{array}{l}\text { Differential } \\
\text { evolution and } \\
\text { particle swarm } \\
\text { optimization }\end{array}$ & $\begin{array}{l}10 \text { thermal without wind } \\
\text { power, IEEE } 118 \text {-bus } \\
\text { with } 14 \text { thermal unit and } \\
1 \text { large wind farm }\end{array}$ & & $\sqrt{ }$ & $\sqrt{ }$ & & & $\begin{array}{l}\text { Wind power chance } \\
\text { constraints, ramp rate limit of } \\
\text { thermal }\end{array}$ \\
\hline 3. & $\begin{array}{c}{[5]} \\
2018\end{array}$ & $\begin{array}{l}\text { MOEA/D and } \\
\text { SMODE }\end{array}$ & IEEE 30-bus & $\sqrt{ }$ & & $\sqrt{ }$ & $\sqrt{ }$ & $\sqrt{ }$ & $\begin{array}{l}\text { Prohibited operating zones and } \\
\text { security constraints }\end{array}$ \\
\hline 4. & $\begin{array}{c}{[1]} \\
2017\end{array}$ & $\begin{array}{l}\text { eFPA and } \\
\text { binary FPA }\end{array}$ & $\begin{array}{l}\text { IEEE } 30 \text {-bus of } 5 \text { thermal } \\
\text { and } 20 \text { solar, IEEE } 57 \text {-bus } \\
\text { of } 5 \text { thermal and } 20 \text { solar }\end{array}$ & $\sqrt{ }$ & & & $\sqrt{ }$ & & Renewable energy constraints \\
\hline 5. & $\begin{array}{l}{[17]} \\
2017\end{array}$ & $\begin{array}{l}\text { NGSA-II } \\
\text { and SPEA -2 }\end{array}$ & $\begin{array}{l}26 \text { buses, } 46 \text { transmission } \\
\text { lines, } 6 \text { thermal and } 2 \\
\text { wind farm }\end{array}$ & & $\sqrt{ }$ & $\sqrt{ }$ & & & $\begin{array}{l}\text { Ramp rate limit, prohibited } \\
\text { operational zones, generation } \\
\text { limit of wind turbines, line } \\
\text { loading limit }\end{array}$ \\
\hline 6. & $\begin{array}{l}{[18]} \\
2017\end{array}$ & $\begin{array}{l}\text { Modified } \\
\text { cuckoo search } \\
\text { algorithm }\end{array}$ & $\begin{array}{l}2 \text { hydro plant and } 1 \\
\text { thermal plant, } 1 \text { hydro } \\
\text { plant } 1 \text { thermal plant, } \\
2 \text { hydro plant and } 2 \\
\text { thermal plant }\end{array}$ & $\sqrt{ }$ & & & & $\sqrt{ }$ & Hydraulic constraints \\
\hline 7. & $\begin{array}{l}{[10]} \\
2016\end{array}$ & $\begin{array}{l}\text { OLHBMO } \\
\text { algorithm }\end{array}$ & $\begin{array}{l}\text { IEEE 30-bus and IEEE } \\
\text { 118-bus }\end{array}$ & $\sqrt{ }$ & & $\sqrt{ }$ & & & $\begin{array}{l}\text { Security constraints, prohibited } \\
\text { operating zones }\end{array}$ \\
\hline 8. & $\begin{array}{c}{[4]} \\
2016\end{array}$ & $\begin{array}{l}\text { PSO, } \\
\text { Newton- } \\
\text { Rahpson and } \\
\text { binary integer } \\
\text { programming }\end{array}$ & $\begin{array}{l}\text { IEEE } 30 \text {-bus of } 6 \text { thermal, } \\
13 \text { solar plant }\end{array}$ & $\sqrt{ }$ & & & $\sqrt{ }$ & & $\begin{array}{l}\text { Renewable energy limit, } \\
\text { network constraints }\end{array}$ \\
\hline
\end{tabular}




\begin{tabular}{|c|c|c|c|c|c|c|c|c|c|}
\hline \multirow[t]{2}{*}{ No. } & \multirow[t]{2}{*}{ Ref/Year } & \multirow[t]{2}{*}{ Method } & \multirow[t]{2}{*}{ Test Case } & \multicolumn{2}{|c|}{ Condition } & \multicolumn{3}{|c|}{$\begin{array}{c}\text { Renewable } \\
\text { Energy Source }\end{array}$} & \multirow[t]{2}{*}{ Constraint } \\
\hline & & & & St & $\mathrm{D}$ & $\mathrm{W}$ & $\mathrm{S}$ & $\mathrm{H}$ & \\
\hline 9. & $\begin{array}{l}{[16]} \\
2016\end{array}$ & $\begin{array}{l}\text { Interior point } \\
\text { algorithm and } \\
\text { normalized } \\
\text { normal } \\
\text { constraints } \\
\text { algorithm }\end{array}$ & $\begin{array}{l}\text { Actual large scale power } \\
\text { system IEEE 39-bus with } \\
\text { wind farm }\end{array}$ & $\sqrt{ }$ & & $\sqrt{ }$ & & $\sqrt{ }$ & $\begin{array}{l}\text { Thermal and hydroelectric } \\
\text { output constraints, } \\
\text { transmission line limit, security } \\
\text { limit }\end{array}$ \\
\hline 10. & $\begin{array}{c}{[9]} \\
2016\end{array}$ & $\begin{array}{l}\text { Interior point } \\
\text { method, } \\
\text { scenario } \\
\text { based } \\
\text { decompositio } \\
\mathrm{n} \text { and } \\
\text { asynchronous } \\
\text { block } \\
\text { iteration }\end{array}$ & $\begin{array}{l}\text { IEEE 39-bus and real } \\
\text { 1534-bus power system }\end{array}$ & & $\sqrt{ }$ & $\sqrt{ }$ & & & $\begin{array}{l}\text { Conventional unit output } \\
\text { constraints, wind farm output } \\
\text { constraints, pump storage } \\
\text { output constraints, network } \\
\text { transmission constraints }\end{array}$ \\
\hline 11. & $\begin{array}{c}{[8]} \\
2015\end{array}$ & $\varepsilon$ constraint & $\begin{array}{l}\text { IEEE } 118 \text {-bus with } 10 \text { oil } \\
\text { fired, } 11 \text { gas fired, } 33 \text { coal } \\
\text { fired units and } 8 \text { hydro } \\
\text { units }\end{array}$ & & $\sqrt{ }$ & & & $\sqrt{ }$ & $\begin{array}{l}\text { Prohibited operational zones, } \\
\text { valve loading effect, capacity } \\
\text { limits of thermal, ramp rate } \\
\text { limit, hydro constraints. }\end{array}$ \\
\hline 12. & $\begin{array}{l}{[15]} \\
2015\end{array}$ & GAEPSO & $\begin{array}{l}6 \text { and } 40 \text { thermal without } \\
\text { wind } \\
40 \text { thermal with } 2 \text { wind } \\
\text { farm }\end{array}$ & $\sqrt{ }$ & & $\sqrt{ }$ & & & Prohibited zones constraint \\
\hline 13. & $\begin{array}{l}{[11]} \\
2014\end{array}$ & $\begin{array}{l}\text { PSO } \\
\text { algorithm }\end{array}$ & 6 thermal 13 solar plant & $\sqrt{ }$ & $\sqrt{ }$ & & $\sqrt{ }$ & & Ramp rate limit \\
\hline 14. & $\begin{array}{l}{[14]} \\
2014\end{array}$ & $\begin{array}{l}\text { Improved } \\
\text { multi- } \\
\text { objective } \\
\text { estimation of } \\
\text { distribution } \\
\text { algorithms }\end{array}$ & $\begin{array}{l}2 \text { hydro plant, } 4 \text { thermal } \\
\text { unit, } 2 \text { hydro plant, } 2 \\
\text { thermal unit }\end{array}$ & $\sqrt{ }$ & & & & $\sqrt{ }$ & $\begin{array}{l}\text { Water availability constraints, } \\
\text { generation limit }\end{array}$ \\
\hline 15. & $\begin{array}{c}{[6]} \\
2013\end{array}$ & GABC & $\begin{array}{l}\text { IEEE 30-bus with } 6 \\
\text { thermal and } 2 \text { wind farm }\end{array}$ & $\sqrt{ }$ & & $\sqrt{ }$ & & & $\begin{array}{l}\text { Prohibited operational zones, } \\
\text { ramp rate limit }\end{array}$ \\
\hline 16. & $\begin{array}{l}{[13]} \\
2013\end{array}$ & $\begin{array}{l}\text { Civilized } \\
\text { swarm } \\
\text { optimization }\end{array}$ & $\begin{array}{l}4 \text { hydro unit, } 3 \text { thermal } \\
\text { unit, } 2 \text { hydro unit, } 4 \\
\text { thermal unit }\end{array}$ & & $\sqrt{ }$ & & & $\sqrt{ }$ & $\begin{array}{l}\text { Operational limits constraints } \\
\text { on hydro and thermal, flow } \\
\text { balance, bound of water } \\
\text { discharge through turbines }\end{array}$ \\
\hline 17. & $\begin{array}{l}{[12]} \\
2012\end{array}$ & $\begin{array}{l}\text { Mixed integer } \\
\text { nonlinear } \\
\text { programming }\end{array}$ & $\begin{array}{l}\text { IEEE } 118 \text {-bus with } 10 \text { oil } \\
\text { fired, } 11 \text { gas fired and } 33 \\
\text { coal fired unit }\end{array}$ & & $\sqrt{ }$ & & & $\sqrt{ }$ & $\begin{array}{l}\text { Prohibited operational zones, } \\
\text { capacity limit constraints, ramp } \\
\text { rate limit, maximize profit }\end{array}$ \\
\hline
\end{tabular}

\section{OPTIMIZATION METHOD OF CEED}

There are different methods have been proposed to handle the power dispatch problem for minimizing cost and emission in power generation. Generally, it can be classified into three categories as shown in Figure 1 which are traditional method, non-conventional method and hybrid method.

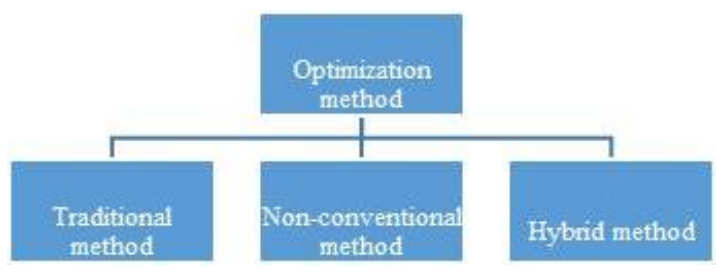

Figure 1. Classification of optimization method

Traditional methods including simulated annealing[20], Lambda iteration [21] and Newton Raphson [22] are usually performed better and fast on single objective function since they don't have problem on specific parameter. As the problem becomes multi-objective function, the non-conventional method is introduced to handle the difficult optimization problem. Various non-conventional method such as, FPA [1], Modified NSGA-II [23], PSO [24], LFA [25],WOA [26],CSA [27] and SOA [28] have been successfully utilized for these problem. 
Even though, the performance is great in solving non-linear and non-convex problem, but some of these meta-heuristic algorithms are suffered from specific parameter selection thus resulting a long computational time. Therefore, a hybrid method is proposed in which combining two or more algorithms with hope to improve the previous single algorithm. The proposed hybrid algorithms such as DSA-DP-CSA [29], MOEA-SMODE [5], PSO-Newton Raphson and binary integer programming [4] and CSA-PSO [13] are efficiently solve the dispatch problem. However, the hybrid method is more difficult and the computational time is longer compared to non-conventional method. Some performances are so much improved than previous but some cases may be worse than previous. Therefore, each algorithm has its own benefit and drawback while thre is no single algorithm can outperform other algorithm for different nature of problem. Table 2 list out the advantages and disadvantages of some optimization methods.

Table 2. Advantages and Disadvantages of Some Optimization Method

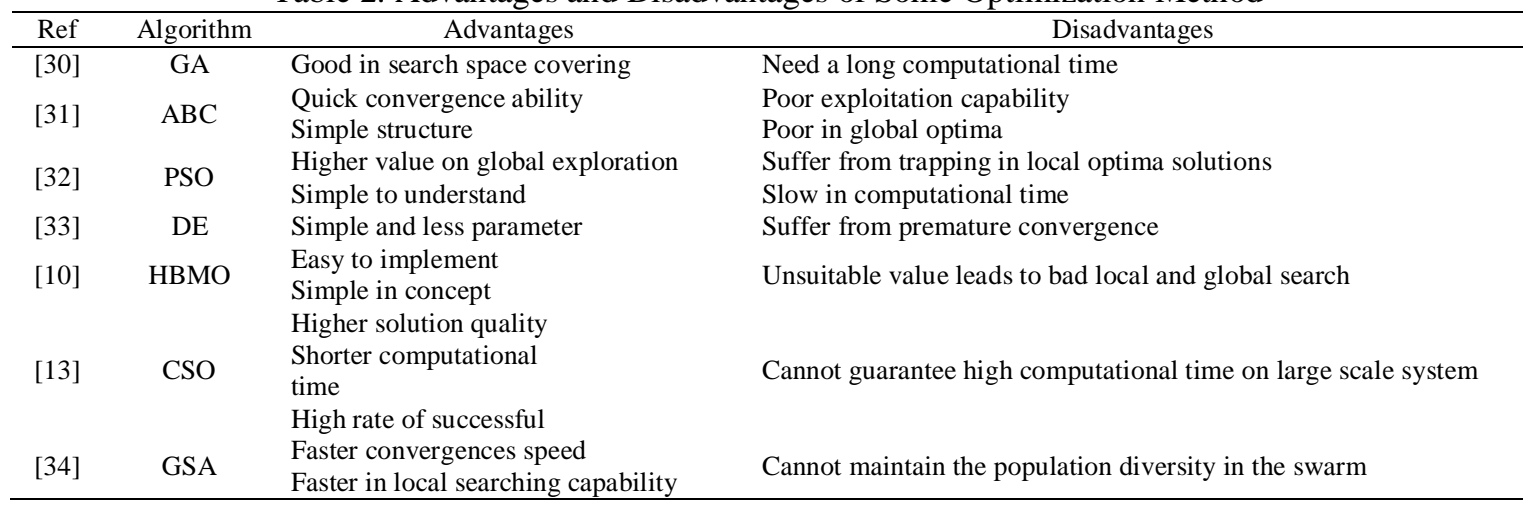

\section{CONCLUSION}

This paper has presented a review of application of renewable energy on combined economic emission dispatch optimization problem with integration of renewable energy. There are different types of renewable energy sources and combinations have been considered in current power dispatch problem and the problem become complex multi-objective optimization problem. Apart from that, the methods, test cases, types of renewable energy, constraints and condition either static or dynamic of each paper are reviewed and tabulated in the table. In order to solve this complex CEED problem, many optimization algorithms have been proposed and each of them have their own advantages and disadvantages. This paper also summarizes the classification of the optimization methods that widely used such as traditional method, non-conventional and hybrid method.

From the review, it found that renewable energy like solar power plant is the large green technology has been integrated in power system over various countries. Therefore, the power dispatch is become complex due to the intermittent sun radiation and required new dispatch model and efficient optimization algorithm. As mention in [35], the factor of convergence, optimal solution, robustness and computational time must be considered in order to find a good solution of optimization technique. Thus, it has a great potential to discover an effective and accurate solution for solving economic emission dispatch optimization problem with integration of renewable energy in static and dynamic condition.

\section{ACKNOWLEDGEMENT}

The Authors would like to thanks to Universiti Tun Hussein Onn Malaysia and Research Fund, UTHM for supporting this project under Geran Penyelidikan Pascasiswazah (GPPS) Vot No. H298.

\section{REFERENCES}

[1] C. Shilaja and K. Ravi, "Optimization of emission / economic dispatch using euclidean affine flower pollination algorithm ( eFPA ) and binary FPA ( BFPA ) in solar photo voltaic generation,” Renew. Energy, vol. 107, pp. 550-566, 2017.

[2] T. Nitin, "Economic load dispatch of wind-solar-thermal system using backtracking search algorithm," Int. J. Eng. Technol., vol. 8, no. 4, pp. 16-27, 2016.

[3] M. Basu, "Multi-area dynamic economic emission dispatch of hydro-wind-thermal power system," Reinf. Plast., vol. 28, no. 00, pp. 11-35, 2019. 
[4] N. A. Khan, G. Ahmad, S. Sidhu, F. Gao, and S. Member, "Optimizing combined emission economic dispatch for solar integrated power systems," vol. 4, 2016.

[5] P. P. Biswas, P. N. Suganthan, B. Y. Qu, and G. A. J. Amaratunga, "Multiobjective economic-environmental power dispatch with stochastic wind-solar-small hydro power," vol. 150, 2018.

[6] H. T. Jadhav and R. Roy, "Expert systems with applications Gbest guided artificial bee colony algorithm for environmental / economic dispatch considering wind power," Expert Syst. Appl., vol. 40, no. 16, pp. 6385-6399, 2013.

[7] A. Immanuel Selvakumar, "Civilized swarm optimization for multiobjective short-term hydrothermal scheduling," Int. J. Electr. Power Energy Syst., vol. 51, pp. 178-189, 2013.

[8] J. Aghaei, A. Ahmadi, A. Rabiee, V. G. Agelidis, K. M. Muttaqi, and H. A. Shayanfar, "Uncertainty management in multiobjective hydro-thermal self-scheduling under emission considerations," Appl. Soft Comput. J., vol. 37, pp. 737-750, 2015.

[9] Y. Fu, S. Member, M. Liu, and L. Li, "Multiobjective stochastic economic dispatch with variable wind generation using scenario-based decomposition and asynchronous block iteration," IEEE Trans. Sustain. Energy, vol. 7, no. 1, pp. 139-149, 2016.

[10] A. Ghasemi, M. Gheydi, M. Javad, and M. Eslami, "Modeling of wind / environment / economic dispatch in power system and solving via an online learning meta-heuristic method," Appl. Soft Comput. J., vol. 43, pp. 454-468, 2016.

[11] N. Ahmed et al., "Combined emission economic dispatch of power system including solar photo voltaic generation,” Energy Convers. Manag., vol. 92, pp. 82-91, 2015.

[12] A. Ahmadi, J. Aghaei, H. A. Shayanfar, and A. Rabiee, "Mixed integer programming of multiobjective hydrothermal self scheduling," Appl. Soft Comput. J., vol. 12, no. 8, pp. 2137-2146, 2012.

[13] A. I. Selvakumar, "Electrical power and energy systems civilized swarm optimization for multiobjective short-term hydrothermal scheduling," Int. J. Electr. Power Energy Syst., vol. 51, pp. 178-189, 2013.

[14] Y. Li, H. He, Y. Wang, X. Xu, and L. Jiao, "An improved multiobjective estimation of distribution algorithm for environmental economic dispatch of hydrothermal power systems," Appl. Soft Comput. J., vol. 28, pp. 559-568, 2015.

[15] S. Jiang, Z. Ji, and Y. Wang, "Electrical Power and Energy Systems A novel gravitational acceleration enhanced particle swarm optimization algorithm for wind - thermal economic emission dispatch problem considering wind power availability," Int. J. Electr. Power Energy Syst., vol. 73, pp. 1035-1050, 2015.

[16] S. Lin, M. Liu, Q. Li, W. Lu, Y. Yan, and C. Liu, "Normalised normal constraint algorithm applied to multiobjective security- constrained optimal generation dispatch of large-scale power systems with wind farms and pumped-storage hydroelectric stations," vol. 11, pp. 1539-1548, 2017.

[17] M. Andervazh and S. Javadi, "Emission-economic dispatch of thermal power generation units in the presence of hybrid electric vehicles and correlated wind power plants," 2017.

[18] T. Trung and D. Ngoc, "Modified cuckoo search algorithm for multiobjective short-term hydrothermal scheduling," Swarm Evol. Comput., vol. 37, no. May, pp. 73-89, 2017.

[19] G. Liu, Y. L. Zhu, and W. Jiang, "Wind-thermal dynamic economic emission dispatch with a hybrid multiobjective algorithm based on wind speed statistical analysis," 2018.

[20] C. Chen, "Simulated annealing-based optimal wind-thermal coordination scheduling," pp. 447-455.

[21] R. Liang, “A Neuragbased Redispatch Approach To Dynamic Generation,” vol. 14, no. 4, pp. 1388-1393, 1999.

[22] J. Chen and S. Chen, "Multiobjective power dispatch with line flow constraints using the fast Newton-Raphson method," vol. 12, no. 1, 1997.

[23] S. Dhanalakshmi, S. Kannan, K. Mahadevan, and S. Baskar, "Application of modified NSGA-II algorithm to Combined Economic and Emission Dispatch problem," Int. J. Electr. Power Energy Syst., vol. 33, no. 4, pp. 992-1002, 2011.

[24] M. A. Meziane and Y. Mouloudi, "An effective non-traditional algorithm for solving the problem of optimal power flow with minimum environmental pollution using price penalty factors," vol. 11, no. 2, pp. 55-74, 2018.

[25] M. Kheshti, X. Kang, J. Li, P. Regulski, and V. Terzija, "Lightning flash algorithm for solving non- convex combined emission economic dispatch with generator constraints," 2017.

[26] C. K. Faseela and H. Vennila, "Economic and emission dispatch using whale optimization algorithm ( WOA )," vol. 8, no. 3, pp. 1297-1304, 2018.

[27] R. Habachi, A. Touil, A. Boulal, A. Charkaoui, and A. Echchatbi, "Solving economic dispatch and unit commitment problem in smart grid system using eagle strategy based crow search algorithm," vol. 14, no. 3, pp. 1087-1096, 2019.

[28] L. Benasla, A. Belmadani, and M. Rahli, "Electrical Power and Energy Systems Spiral optimization algorithm for solving combined economic and emission dispatch," Int. J. Electr. Power Energy Syst., vol. 62, pp. 163-174, 2014.

[29] B. Ming, P. Liu, L. Cheng, Y. Zhou, and X. Wang, "Optimal daily generation scheduling of large hydro photovoltaic hybrid power plants," Energy Convers. Manag., vol. 171, no. June, pp. 528-540, 2018.

[30] X. Yan and Q. Wu, “An improved genetic algorithm and its application,” vol. 10, no. 5, pp. 1081-1086, 2012.

[31] K. C. S. P. Simon, "Multi-objective unit commitment problem with reliability function using fuzzified binary real coded artificial bee colony algorithm," vol. 6, no. June 2011, pp. 1060-1073, 2012.

[32] M. A. Meziane, Y. Mouloudi, and B. Bouchiba, "Impact of inertia weight strategies in particle swarm optimization for solving economic dispatch problem," vol. 13, no. 1, pp. 377-383, 2019.

[33] Y. Lu, J. Zhou, H. Qin, Y. Wang, and Y. Zhang, "Engineering applications of artificial intelligence chaotic differential evolution methods for dynamic economic dispatch with valve-point effects," Eng. Appl. Artif. Intell., 
vol. 24, no. 2, pp. 378-387, 2011.

[34] U. Güvenç, Y. Sönmez, S. Duman, and N. Yörükeren, "Sharif University of Technology Combined economic and emission dispatch solution using gravitational search algorithm," Sci. Iran., vol. 19, no. 6, pp. 1754-1762, 2012.

[35] F. Parvez, P. Vasant, V. Kallimani, and J. Watada, "A holistic review on optimization strategies for combined economic emission dispatch problem,” Renew. Sustain. Energy Rev., no. June, pp. 1-15, 2017.

\section{BIOGRAPHIES OF AUTHORS}

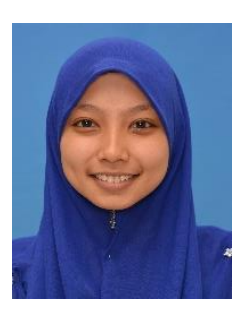

Nadia Farisha binti Aswan received the bachelor's degree in electrical engineering from Universiti Tun Hussein Onn Malaysia, Johor, Malaysia in 2017, where she is pursuing the master degree in electrical engineering. Her research interest include power dispatch, renewable energy sources and optimization algorithms.

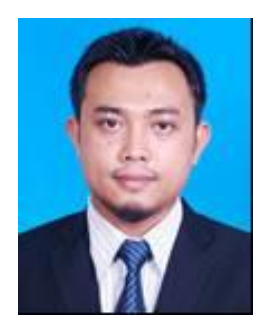

Mohd Noor Abdullah received his B.Eng. (Hons) in Electrical Engineering and M. Eng. in Electrical Engineering (Power System) from Universiti Teknologi Malaysia (UTM) in 2008 and 2010 respectively. He also received a Ph.D degree in Electrical Engineering from University of Malaya (UM) in 2014. He has been with Universiti Tun Hussein Onn Malaysia (UTHM) from 2008 to 2014 as a tutor. He is currently as a Lecturer in Department of Electrical Power Engineering, Faculty of Electrical and Electronic Engineering (FKEE), Universiti Tun Hussein Onn Malaysia (UTHM). He also appointed as a head of Green and Sustainable Energy (GSEnergy) Focus Group in FKEE, UTHM. He was a member of Board of Engineer Malaysia and IEEE. His research interests are electric power dispatch, distributed generation, renewable energy and meta-heuristic optimization techniques.

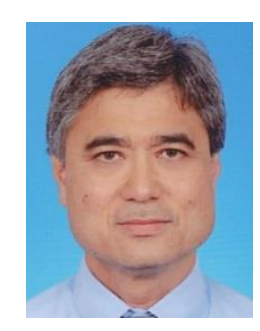

Prof Ir Dr Ab Halim Abu Bakar received the B.Sc. degree in Electrical Engineering from the University of Southampton, United Kingdom in 1976, M.Eng. and Ph.D. degrees from the University of Technology, Malaysia in 1996 and 2003 respectively. He spent 30 years of industrial experience with Tenaga Nasional Berhad (TNB) before joining University of Malaya. Prof Ir Dr Halim is a Fellow of the Institute of Engineers Malaysia, Member of IEEE, Cigre, Chartered Engineer (UK) and P.Eng (Malaysia). Currently he is a professor with the UM Power Dedicated Advanced Centre (UMPEDAC), University of Malaya, Malaysia. He is an established academician and a practical engineer. He has to-date published 89 ISI and 151 Scopus papers in journals and 47 papers in proceedings internationally. He has successfully supervised to completion $14 \mathrm{PhD}, 5$ master by research (M.Eng.Sc), 1 master of philosophy (M.Phil) and 50 Masters by course work project (M.Eng) and has Web of Science H index of 20 and Scopus H index of 22 is also involved as a reviewer for international journal such as IEEE Transactions Power Delivery, IEEE Transactions Power Systems, IEEE Smart Grid, IET Generation, Transmssion and Distribution IJEPES (Elsevier) and several international conferences. Prof Ir Dr Halim won several excellent awards during his professional and academic carrier. In 2008 he won IEEE PES Malaysian Chapter Outstanding Engineering Award. His research interest include power system protection and power system transients. 